\title{
Una reforma educativa desconocida El Salvador I883-1890'
}

JuLián GonZÁlez ToRRES

Departamento de Filosofía UCA, El Salvador

... el Gobierno tiene pensado hacer una reforma amplia y eficaz, encaminada á remover obstáculos y á extirpar vicios que han impedido que la enseñanza llegue en nuestro país, á la altura que reclama el siglo. ${ }^{2}$

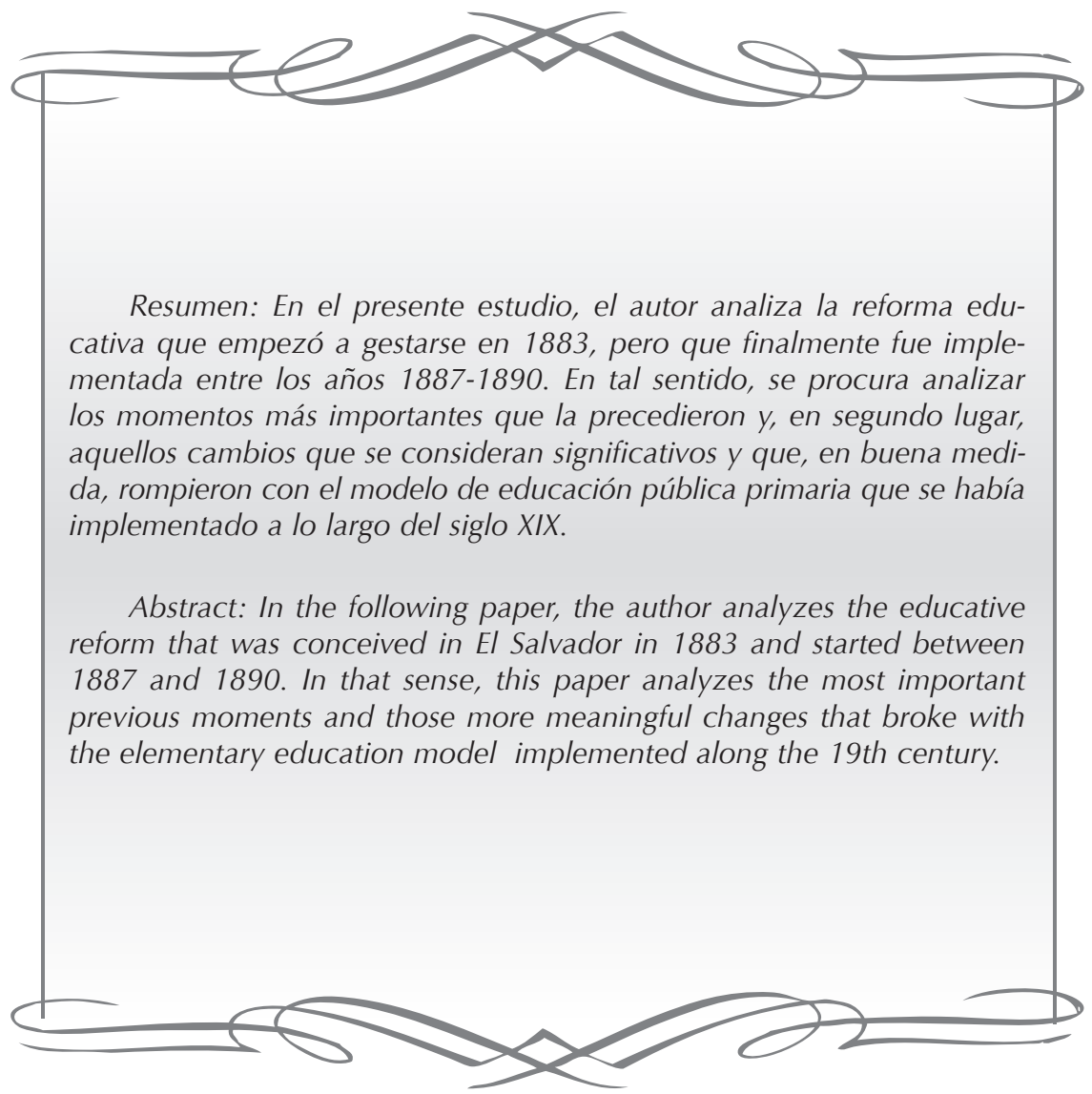


$\mathrm{E}$ s común, en El Salvador, que al hablar de educación pública primaria se piense que los mejores proyectos educativos fueron obra del siglo XX. Este es el caso, por ejemplo, de Manuel Luis Escamilla, cuando afirma que: "De acuerdo con la historia de las ideas pedagógicas de El Salvador, la era moderna de la educación comienza con la llegada de una Misión Alemana a dirigir la Escuela Normal de Maestros, en 1924". ${ }^{3}$ En realidad, la modernización del sistema estatal de educación primaria se gestó, en gran medida, en la década de 1880, específicamente con la reforma ejecutada entre los años 1887-1890; transformación educativa que, a mi criterio, es la gran desconocida entre pedagogos e historiadores de la educación en El Salvador. Mi propósito es, por lo tanto, sacarla a la luz.

$Y$ es que a lo largo de la segunda mitad del siglo XIX, en varios países de América Latina se Ilevaron a cabo reformas educativas cuyo objetivo principal era modernizar la educación que impartían los Estados. Los reformadores entendían por modernizar: (1) renovar o refundar los principios, métodos y contenidos de enseñanza en las escuelas públicas; (2) ampliar o expandir la instrucción del pueblo, lo cual requería un mayor control de la educación por parte del Estado; y (3) hacer de la educación estatal una educación laica. De ahí que encontraremos medidas o políticas muy parecidas en países como Ar- gentina, ${ }^{4}$ Colombia,${ }^{5}$ Costa Rica,${ }^{6}$ México $^{7}$ y el mismo El Salvador. Me refiero a medidas como las siguientes: (a) reestructuración de las escuelas públicas en base al sistema de grados progresivos; (b) introducción de asignaturas como Historia Nacional o Historia Patria, Economía Doméstica, Gimnasia y Ejercicios Militares; (c) creación de escuelas normales para formar docentes; (d) introducción de prácticas pedagógicas consideradas exitosas en países como Estados Unidos y Alemania; (e) mayor control y centralización de la educación pública primaria por parte del Estado; (f) lucha por la escuela laica; etc.

Aquella reestructuración o renovación de los sistemas nacionales de educación debe comprenderse en el contexto de las reformas de corte liberal, impulsadas por distintos gobiernos a lo largo y ancho de América Latina. Liberales confesos, muchos de ellos francmasones, inspirados en los valores de la llustración, seguidores de los principios abanderados por la Revolución francesa y admirados por el progreso de la República estadounidense, se dieron a la tarea de refundar sus respectivas naciones. Ello implicó, entre otras cosas, abolir el carácter oficial del credo católico, decretar el Estado laico, instaurar la libertad de culto, la secularización de los cementerios, el matrimonio civil, proponer el voto para las mujeres ${ }^{8}$ y, por supuesto, refundar la educación primaria. En las siguientes 
páginas analizaremos aquellos elementos de la reforma educativa que fueron más decisivos para la historia político-educativa de El Salvador.

\title{
I. Gestación de una reforma
}

\subsection{Por una reforma amplia y eficaz}

El 2 de febrero de 1880, Salvador Gallegos, Ministro de Instrucción Pública y Beneficencia, ex- presaba ante el Congreso Nacional Constituyente que más que multiplicar escuelas a lo largo y ancho de la República, lo que se requería era dotar a las ya existentes:

\begin{abstract}
... de buenos directores, y de testos y elementos adecuados, para que bajo un método uniforme y apropiado á la inteligencia de los niños, se vayan desenvolviendo en ellos las aptitudes, de que más tarde tienen que hacer uso, preparando así a los ciudadanos para las múltiples funciones de la vida civilizada. ${ }^{9}$
\end{abstract}

El texto del ministro es revelador en la medida en que manifestaba abiertamente la necesidad de implementar "un método uniforme" de enseñanza. A ello hay que agregar dos preocupaciones más que Gallegos externalizó en su informe ante el Poder Legislativo: (1) la falta de una adecuada inspección por parte del Gobierno Central del trabajo realizado en los centros escolares; (2) la contribución económica para las escuelas que el Estado exigía a los padres de familia. Lo primero impedía al Estado tener un control más efectivo de las escuelas. Lo segundo era una medida desigual, ya que los más pobres, que eran la mayoría, por lo general no podían aportar la contribución estipulada. ${ }^{10}$ Frente a ese conjunto de problemáticas, Gallegos terminaba diciendo que el Gobierno "se propone introducir saludables re- formas en las leyes que reglamentan la instrucción primaria". Este espíritu reformista sería retomado por su sucesor: el Doctor Domingo López.

López se desempeñó como Ministro de Instrucción Pública y Beneficencia de 1880 a 1883. Continuando con la tradición, y al cierre del segundo período presidencial de Rafael Zaldívar, López se presentó el 30 de enero de 1884 ante el Cuerpo Legislativo -entiéndase las dos Cámaras juntas, de Senadores y Diputados, reunidas en Asamblea General-. Su objetivo: rendir el informe correspondiente a las labores ejecutadas durante 1883. El ministro López reafirmó ante la Asamblea General el interés gubernamental por reformar la instrucción pública primaria. Se dirigió al Poder Legislativo en los siguientes términos: 
En las evoluciones incesantes de la historia, cada época, cada siglo ha marcado una fase en el desenvolvimiento de la civilización, desarrollando algunos de los elementos del progreso, aquel que se ha tenido como el móvil más conducente á la perfección humana. Pues bien, el móvil en que se inspira nuestro siglo, la fase que lo caracteriza es la enseñanza popular, medio único de la realización de los derechos y de las libertades sociales y políticas; pero para que su desarrollo sea completo, menester es que aquella sea gratuita y obligatoria: gratuita, para que pueda penetrar hasta las más desvalidas clases de la sociedad; obligatoria, porque como vosotros sabéis, nuestros pueblos aún se resienten de la mala educación colonial (...). ${ }^{11}$

López enfatizó que la educación primaria debía ser gratuita y obligatoria. En principio, esto garantizaría dos cosas: (1) obligar a los padres de familia a enviar a sus hijos a la escuela, y así el Estado se asegura de educar a sus futuros ciudadanos; (2) que hubiesen menos excluidos de la educación por razones económicas.

En cuanto al segundo punto, el gobierno de Zaldívar había dado un paso importante. En abril de 1881 emitió un decreto que suprimía "la contribución directa de los padres de familia, no solo contraria al espíritu de nuestra Carta Fundamental [la cual había ratificado el carácter obligatorio y gratuito de la educación pública], sino odiosa en sí misma y causa de repulsión degradante que en muchos lugares se observa por la enseñanza obligatoria". ${ }^{2}$

En el año de 1879, el Gobierno Central había desembolsado 53,676 pesos en concepto de sueldo para los profesores; mientras que para ese mismo rubro los padres de familia hicieron un aporte total de 36,879 pesos. $^{13}$ Cuatro años más tarde, en 1883, ya no se hablaba de aporte de padres de familia, sino de "parte pagada por particulares". El aporte total de éstos fue de 5,581 pesos; el Gobierno Central, por su parte, tuvo una erogación de 93,728 pesos. ${ }^{14}$ El cambio era muy significativo, lo cual demuestra que el Estado salvadoreño estaba haciendo esfuerzos por convertir la instrucción pública primaria en un servicio enteramente gratuito. En otras palabras, podríamos decir que el Poder Ejecutivo había interpuesto sus buenos oficios ante la crítica que hiciera Gallegos, predecesor de López, a la contribución exigida a los padres de familia.

Por otro lado, López advertía que "nuestros pueblos" aún cargan con efectos de la "mala educación colonial". Es muy probable que el ministro se refiriera a la enseñanza 
de la doctrina cristiana que había predominado durante el siglo XIX. Es importante mencionar que tres años atrás, específicamente el 15 de julio de 1880, el Sub-Secretario de Instrucción Pública, Antonio J. Castro, había girado una circular a todos los gobernadores departamentales del país. En dicha misiva les pedía que de inmediato prohibieran en las escuelas estatales la enseñanza del Catecismo del Padre Ripalda. Evidentemente, hubo resistencias a tal disposición gubernamental.
De tal manera que el Gobierno de Zaldívar dispuso multar con 200 pesos a aquellos gobernadores que mostrasen incapacidad en cuanto a hacer cumplir la circular emitida. ${ }^{15}$ No obstante, el reclamo del Ministro López hace pensar que probablemente la doctrina cristiana católica se continuaba enseñando en muchas escuelas públicas, lo cual impedía, en buena medida, la implementación de una enseñanza más amplia y laica. Por eso advertía López:

... el Gobierno tiene pensado hacer una reforma amplia y eficaz, encaminada á remover obstáculos y á extirpar vicios que han impedido que la enseñanza llegue en nuestro país, á la altura que reclama el siglo. ${ }^{16}$

\subsection{Un concurso de obras de pedagogía}

En coherencia con la Constitución aprobada en febrero de 1880 , la cual establecía en el artículo 66 que era obligación del Poder Legislativo "procurar el desarrollo de la instrucción pública, en todos los ra- mos del saber humano, decretando estatutos y métodos adecuados", ${ }^{17}$ en febrero de 1883 el presidente de la Cámara de Senadores, Teodoro Moreno, sometió a discusión de aquella un proyecto relativo a la instrucción pública. Así registró el Diario Oficial aquel hecho:

Púsose á discusión... El dictamen de la comisión de Instrucción Pública, en un proyecto del señor Senador [Teodoro] Moreno, sobre que se convoque un concurso de pedagogos á fin de que escriban una obra relativa á los principios, métodos, materias y programas más adecuados para la enseñanza primaria de la República; habiéndose aprobado la parte resolutiva que dice: "La comisión opina: que le deis vuestra aprobación"..18

Como fruto de aquélla moción, la Cámara emitió un decreto mediante el cual ordenaba al Poder
Ejecutivo la inmediata apertura de un concurso de obras de pedagogía. Habiendo asumido el principio 
de que "la educación primaria es la base verdadera en que se debe fundar el progreso de un país", los senadores autorizaban al Ejecutivo para que reorganizara la educación pública primaria de acuerdo a lo que estableciera la obra que resultase ganadora. La premiación debía realizarse en septiembre de aquél mismo año, de acuerdo a los montos establecidos para los tres primeros lugares. El premio para el primer lugar consistiría en 1,500 pesos; 1,000 pesos para el segundo lugar y 500 para el tercer lugar. ${ }^{19} \mathrm{Sin}$ embargo, el Gobierno prorrogó la fecha de la premiación. Es muy probable que se pospusiera debido a la crisis financiera que en ese momento ya sufría el Gobierno de Zaldívar. Según Antonio Acosta, en 1883 los ingresos fiscales del Estado se redujeron considerablemente debido al hundimiento de las rentas aduaneras, como resultado de la caída de las importaciones nacionales. ${ }^{20} \mathrm{La}$ premiación tuvo lugar hasta el 23 de mayo de 1886, bajo el Gobierno del General Francisco Menéndez.

El primer lugar lo ganó Elementos de pedagogía, obra escrita por Francisco Esteban Galindo; el segundo lugar fue para De la organización de la instrucción primaria en El Salvador, de David J. Guzmán. A pesar de que el decreto ordenaba premiar el tercer lugar, éste fue declarado desierto por el Jurado Calificador.

Una vez hecho público el veredicto, el Gobierno no sólo ordenó el pago en concepto de premio a los autores ganadores, sino que aprobó la publicación de las obras, libros que terminarían convirtiéndose en textos escolares para uso de los profesores. ¿Qué significado cobraría todo esto? ¿A qué le apostaban o qué fines perseguían la Cámara de Senadores y aquellos dos Gobiernos, Zaldívar y Menéndez, con la realización de aquel concurso?

Ambos poderes (Legislativo y Ejecutivo) admitían la necesidad de reformar los principios, métodos y contenidos de enseñanza en las escuelas públicas del país. Reforma que debía tener como modelos aquellos sistemas educativos que hubiesen demostrado progresos significativos en otros países. Según el dictamen del Jurado premiador, "una de las primeras cosas que reclama nuestra patria es introducir los métodos y sistemas puestos en práctica en los países más avanzados en materia de educación". ${ }^{21}$ De esto se colige que el Jurado aspiraba a que se implantara en las escuelas de la República el método pedagógico fundado por Johann Heinrich Pestalozzi (1746-1827) e innovado por Friedrich Fröbel (1782-1852). Dicho método había tenido éxito en lugares como Prusia, Holanda, Gran Bretaña y los Estados Unidos. ${ }^{22}$ En Hispanoamérica tuvo influencia durante la segunda mitad del siglo XIX en países como Colombia, ${ }^{23}$ Costa Rica, ${ }^{24}$ y México, ${ }^{25}$ entre otros. 


\subsection{El proyecto reformista de Rafael Reyes}

Reyes no se desempeñó como Ministro de Instrucción Pública, pero fue un luchador incansable en favor de la educación laica, lucha que le granjeó serias enemistades por parte de aquellos que estaban a favor de que continuara la enseñanza católica en las escuelas públicas. ${ }^{26}$ Además, fue profesor tanto del Colegio Normal de Señoritas, como de la Escuela Normal de Varones; de ésta última, incluso, fue Director entre 1881 y 1883. En el Colegio impartió las materias de Gramática Castellana, Composición, Álgebra y Geometría; mientras que en la Escuela impartió Pedagogía, Retórica e Historia. Por otro lado, Reyes se destacó como miembro de la masonería salvadoreña y jugó un papel político relevante en los tiempos previos a las elecciones para la Asamblea Constituyente de $1885 .^{27}$ Y, por supuesto, mostró un profundo interés por mejorar la instrucción pública primaria. Fue tal su interés que en febrero de 1884 presentó un proyecto de reforma al Ministro de Instrucción Pública y Beneficencia, Luciano Hernández, inmediato sucesor de Domingo López. Su proyecto comprendía dos grandes apartados, uno de análisis crítico y otro de propuestas. Comienza el autor con el planteamiento crítico, exponiendo diez grandes problemas que aquejaban a la enseñanza popular, es decir, la que impartía el Estado:

1. La falta de idoneidad de los profesores;
2. La falta de método en la enseñanza;

3. La falta de un programa bien combinado;

4. La escasa dotación de los profesores;

5. La doble ocupación de Maestro de escuela y de Secretario municipal ó de Juzgado de Paz;

6. La irregularidad en la falta de asistencia á las escuelas;

7. La incuria de las autoridades locales;

8. La incuria de los padres de familia;

9. La imperfección de los exámenes;

10. La falta de conferencias departamentales de maestros, para imponerse el Gobierno de los métodos y marcha de la enseñanza, y uniformarlos en lo posible. ${ }^{28}$

Al igual que el decreto para el concurso de obras de pedagogía y el ex ministro Salvador Gallegos, Reyes insistía en la necesidad de un nuevo método de enseñanza. Por aquella época, según Jorge Alfaro Jovel, se continuaba enseñando con el método lancasteriano. ${ }^{29}$ Respecto a "la falta de un programa bien combinado", Reyes hacía alusión a la necesidad de un sistema de grados progresivos, es decir, un programa mediante el cual 
los niños llevaran en orden escalonado, en base a grados, su proceso de aprendizaje. Entre otras cosas, denunciaba la escasa preparación de los profesores y la necesidad de insumos escolares para que aquéllos desempeñasen bien su trabajo. Así cerraba Reyes su crítica, a la vez que planteaba su alternativa:

Los alumnos que han cursado las materias de enseñanza primaria y han sufrido el examen anual, vuelven á estudiar la mismas materias al año siguiente, sin plan alguno; es decir en las clases de enseñanza primaria se confunden los de primero con los de segundo y tercer año, y de ahí viene el entorpecimiento que se nota en los estudios. De ahí viene que no se pueda apreciar el progreso de una escuela.

Es, pues, de suma necesidad fijar un programa y dividir ordenadamente por años las materias que se deben estudiar, y hacer en dos ó tres años el estudio de ramos extensos ó importantes como la Gramática, la Aritmética, la Historia \&...

En resumen la esencia de las reformas consiste en la división metódica de los ramos de enseñanza primaria, - en la clasificación de escuelas de 1. ${ }^{a}, 2 .^{a}$ y $3 .^{a}$ clase, habida consideración al adelanto de las poblaciones, y en el establecimiento de escuelas anexas - (..... ${ }^{30}$

Es decir, la educación debía comprender tres años (o cursos) y las escuelas se clasificarían en escuelas de primera, segunda y tercera clase. Las de primera (ubicadas en las cabeceras departamentales) y segunda clase (situadas en las cabeceras de distrito) ofrecerían los tres años de estudio. Mientras que las de tercera clase ("las que correspondan á las demás poblaciones", en palabras de Reyes) solamente impartirían primer y segundo año. En el cuadro 1 de los Anexos puede apreciarse la propuesta de plan de estudios de Rafael Reyes.
En junio de 1885, un nuevo movimiento político sacó del poder al entonces presidente Rafael Zaldívar y designó a Francisco Menéndez como su sucesor. $Y$ fue Menéndez quien finalmente llevó a cabo la tan esperada reforma educativa. Prácticamente inició en 1887 y duraría hasta el fin de su gobierno (1890). En las páginas restantes, analizaremos los principales logros de aquella (desconocida) reforma educativa. 


\subsection{El sistema de grados progresivos}

La lógica de los grados progresivos consistía en que los niños y niñas desde el momento en que se incorporaran al sistema escolar, debían someterse a un proceso de aprendizaje que engranaba dos variables fundamentales en toda educación sistematizada: tiempo y contenidos de aprendizaje. La categoría que aunaría ambos componentes sería el grado. Un grado sería un año de estudios logrado. De manera que una vez que el estudiante hubiese finalizado su primer grado, debía pasar al segundo y luego al tercero, y así hasta completar su primaria. ${ }^{31} \mathrm{~A}$ medida que el estudiante avanzara, el contenido de las materias básicas debía irse profundizando y nuevas materias irían incorporándose al currículo. El reglamento aprobado en mayo de 1889 estableció cuatro tipos de escuelas primarias: "Art. 9. —Las escuelas Primarias de la República se dividen en Superiores, Medias, Elementales y Rurales".

Se estableció un máximo de seis grados. Las escuelas Elementales tendrían sólo dos grados (primero y segundo); las Medias tendrían cuatro grados (primero, segundo, tercero y cuarto); mientras que las escuelas Superiores contarían con todos los grados (desde primero hasta sexto)..$^{32}$ En el cuadro 2 puede verse cómo quedó ordenado el sistema según grados, materias y tipo de escuelas.

Evidentemente, los niños y niñas mejor beneficiados serían aqueIlos que tuviesen la oportunidad de formarse en una escuela Superior. No obstante, la fundación de estas escuelas se limitó a las capitales de los departamentos. Pero a pesar de esta limitación, el reglamento fue bien claro en advertir lo siguiente: "es regla invariable que en donde haya una [escuela superior] de varones habrá otra de mujeres". El Gobierno cumplió con tal disposición. Al menos así lo decían los informes del Ministerio de Instrucción Pública. En 1890 El Salvador contaba en sus departamentos — sin contar San Salvador y La Libertad- con 24 escuelas superiores, una de niños y una de niñas en cada cabecera departamental. ${ }^{33}$ Todas sumaban un total de 2,496 estudiantes matriculados: 1,362 niños y 1,134 niñas. De acuerdo al mismo reglamento, a dichas escuelas se les proporcionaría mayor cantidad de útiles y textos escolares.

Sin embargo, fueron las escuelas Elementales y Rurales las que siguieron predominando a lo largo y ancho de la República. El Estado salvadoreño aún no estaba en la capacidad de expandir más el modelo 
de escuelas Superiores. Sin embargo, el sistema de grados progresivos es una herencia de aquella reforma que aún pervive en nuestros tiempos. En la actualidad, la educación básica se divide en tres ciclos (primer, segundo y tercer ciclo), cada uno comprende tres grados (de un total de nueve).

\subsection{Un nuevo currículo en las escuelas}

Toda transformación educativa intenta ser, a mediano o largo plazo, una reforma social y cultural. Los reformadores salvadoreños lo sabían y no se guardaron nada al respecto. Refundar el plan de estudios significaba, esencialmente, dos cosas: eliminar un conjunto de contenidos de aprendizaje e incorporar otros. Pero no se trataba de una simple operación de suma y resta. Era algo más profundo lo que estaba en juego: a mediano plazo, contar con un nuevo tipo de mentalidad entre los ciudadanos; a largo plazo, construir una sociedad diferente. Una sociedad fundamentada en la pluralidad de ideas religiosas, la tolerancia, el conocimiento científico y en la convivencia de sujetos autónomos, conocedores de sus derechos y deberes.

En 1887, el Ministro Baltasar Estupinián decía que "las escuelas primarias... son el laboratorio del porvenir", pero al mismo tiempo reclamaba que no "dán el abundante número de ciudadanos que debían darnos" ${ }^{34}$ Reconocía el importante papel que cumple la escuela en la sociedad, por eso anhelaba un "laboratorio" distinto, ya no aquél donde se enseñaba un conjunto de prescripciones religiosas y una lealtad a Dios y la Santa Iglesia. Si se aspiraba a una nueva sociedad, entonces había que transformar una de sus instituciones insignes: la escuela. Por eso insistía: "Nuestra educación... hay que levantarla á la altura de los adelantos modernos. Apegados á la tradición, bien hallados con añejas prácticas, cuesta trabajo conducir la sociedad á la realización de los ideales que entrañan el porvenir de nuestra patria". ${ }^{35}$ Eliminar la enseñanza del credo católico de las escuelas públicas sería una de las principales conquistas del nuevo currículo establecido por la reforma.

Pero hay que tener presente que fue bajo el segundo período presidencial de Zaldívar (18801884) que el Estado salvadoreño decidió prohibir la enseñanza de la religión católica en las escuelas, específicamente en julio de 1880. El esfuerzo estatal por laicizar la escuela primaria se dio mucho antes de que se reformulara todo el plan de estudios. Además, hay que recordar que el proyecto de reforma que Rafael Reyes presentó al Ministro Luciano Hernández, en febrero de 1884, ya no contemplaba la enseñanza del credo católico. Es decir, desde 1880, el Estado salvadoreño, a través del Sub-Secretario 
de Instrucción Pública, Antonio J. Castro, se había propuesto laicizar las escuelas públicas primarias de la República.

Por tanto, no es del todo cierto, como ha sugerido Margarita Silva Prada, que con la introducción de la materia Historia Sagrada los reformadores contradijeron su espíritu laicista. ${ }^{36}$ Historia Sagrada y Doctrina Cristiana no eran equivalentes. Esta última, además de su fin claramente doctrinario (aprender los diez mandamientos de la Ley de
Dios, memorizar el Credo, aprender a rezar el Padre Nuestro, etc.), instruía al alumno en el conocimiento y obediencia a otro poder, el de Roma, lo cual ya no sería tolerado por aquellos liberales radicales. La otra asignatura, por su parte, era esencialmente histórica y apuntaba a un tipo de moral con arraigo religioso, pero no de carácter catequético y sectario. Esto puede constatarse en las palabras del autor del libro que probablemente sirvió de texto para la asignatura:

La Biblia es un gran libro de moral, y ha sido también y será siempre una de las fuentes más fecundas de la grande poesía. Mi plan ha consistido pues, en reproducir los más bellos pasajes con la animación y el colorido del original del que no me he apartado un solo instante, según llevo dicho. ${ }^{37}$

Esta interpretación de Duruy será compartida por Pedro Flores. Éste — en calidad de Director de la Escuela Primaria de niños, del Barrio Remedios, en San Salvador-, en diciembre de 1886, envió un informe de labores a la Junta de Instrucción Departamental y a la Comisión de Vigilancia. En dicho documento Flores afirmaba lo siguiente:

\section{... todos los sábados les doy una clase oral de Historia Sagrada, pues aunque este último ramo no lo determina el Reglamento [de 1873], siempre he creído que la narración sencilla é infantil de los pasajes bíblicos, suministra máximas de profundo sentido moral que, más tarde, germinan bené- ficas en el corazón de la niñez. ${ }^{38}$}

Podríamos interpretar lo anterior de la siguiente manera: el Catecismo de Ripalda instruía en la fe católica y en la obediencia a la Iglesia. La materia Historia Sagrada, en cambio, a través de relatos bíblicos, no de dogmas, pretendía moralizar a los alumnos. Cuestión esta más abierta y en esencia no dogmática, en la línea de aprender a vivir una fe razonada y -aunque le resultara chocante a la Iglesia- 
tolerante hacia otro tipo de credo religoso. Por su puesto, en la práctica cualquier profesor podría terminar enseñando la clásica doctrina cristiana. Pero ese no era el espíritu de la materia. ${ }^{39}$

Además, hay que advertirlo desde ya, ser liberal laicista para la época no era sinónimo de ser ateo. Los reformadores creían en Dios como cualquier salvadoreño. Ellos luchaban para que ya no se enseñara una religión concreta en las escuelas. Distinguían muy bien entre enseñar y predicar un dogma, por un lado, y apelar a Dios como principio de vida, por otro. Lo primero debía cambiar en las escuelas; lo segundo sería cuestión personal de cada quien. En definitiva: consideramos que la existencia de la materia Historia Sagrada en las escuelas de niños y niñas no violó el carácter laico de la educación sancionado por la Constitución de 1883. El cuadro 3 muestra, en forma comparativa, la radical transformación que sufrió el currículo de las escuelas públicas.

Otro logro significativo fue la incorporación oficial (es decir, reglamentada) de la materia Enseñanza Objetiva, en mayo de 1889. Enfatizo en el carácter "oficial" porque, en realidad, la materia ya se venía impartiendo desde 1887. El objetivo de esa materia era que los niños aprendieran mediante la observación, descripción, análisis y experimentación de las cosas. Se es- peraba que mediante esta los niños y niñas desarrollaran las diferentes habilidades de sus sentidos para que comprendiesen mejor el mundo que los rodeaba. También es importante destacar la incorporación de materias como Fisiología, Zoología, Física, Botánica y Cosmografía. Considero que harán falta investigaciones que estudien las ideas o los imaginarios científicos que le dieron sustento teórico a estos nuevos contenidos de aprendizaje.

\subsection{Hacia una mejor inspección de las escuelas}

La inspección y vigilancia de las escuelas públicas eran precarias. En forma de cascada, la máxima autoridad en materia de educación primaria era el Ministro (o su nombre equivalente) de Instrucción Pública. En segundo lugar estaba la Dirección General de Instrucción Primaria, conducida por un Director General. Después estaban las Juntas Departamentales de Instrucción Pública, cuyo presidente era el Gobernador de cada departamento. Bajo la coordinación y supervisión de las Juntas estaban las Comisiones de Vigilancia, presididas por los alcaldes de los municipios. ${ }^{40}$ En el último peldaño estaban los directores de escuelas y los respectivos profesores.

En el lenguaje de la Dirección General, todos aquellos involucrados en la vigilancia de la educación primaria eran inspectores. Así lo 
establecía el reglamento: "La inspección se divide en local, departamental y general, y los individuos que la ejercen se llaman en general INSPECTORES". ${ }^{41}$ La inspección local era competencia de la Comisión; la departamental, de la Junta; y la inspección general dependía del Director General. Por tanto, en forma ascendente, uno de los principales deberes de los directores de escuelas era "dar cada tres meses á la Comisión de vigilancia respectiva, un informe claro y detallado sobre la marcha y estado de la escuela"; a su vez, era obligación de la Comisión "informar cada tres meses á la Junta de Instrucción pública departamental sobre el estado de la Instrucción primaria en la población [que comprendiese el respectivo municipio]"; la Junta, por su parte, debía "informar trimestralmente al Director General de Instrucción Primaria sobre la marcha de la instrucción en el Departamento, y proponerle las medidas que reclame su desarrollo"; finalmente, el Director General debía "examinar los informes de las Juntas..., de las Comisiones... y de los Directores..., á fin de adquirir un conocimiento exacto y completo de la marcha de todas las escuelas en la República, y de cerciorarse que las leyes, reglamentos; métodos y demás disposiciones sobre Instrucción pública, se cumplen eficazmente" ${ }^{42}$

A decir verdad, era excesiva burocracia. El Gobierno Central dependía enteramente de los informes de las Comisiones y las Juntas. Si se deseaba centralizar la inspección, era necesario operar cambios en esa compleja y lenta estructura. ¿Qué cambios introducirían los reformadores? ¿Pudo establecer el Gobierno Central un control más directo sobre las escuelas de la República? Veamos.

El seis de mayo de 1887, Víctor Dubarry, en calidad de Inspector General de Educación Primaria, despachó una circular a todos los directores de escuelas. Así se expresaba Dubarry en dicha misiva:

Juzgo, sí, indispensable, manifestar á Ud. que esta Inspección desea que la enseñanza mejore, guiada por un buen sistema, y encaminada con toda la uniformidad necesaria. Sobre el sistema que ha adoptado, haré á Ud. frecuentes pormenorizadas indicaciones.

A fin de que pueda yo formarme idea perfecta de lo que necesito hacer en beneficio de la escuela que Ud. dirige, espero que Ud., sin pérdida de tiempo, me suministre informes acerca de los siguientes puntos:

1. En qué estado se halla su escuela. 
2. Qué mobiliario y qué útiles hay, y cuáles se necesitan.

3. Si el local de la escuela es municipal ó de propiedad particular [privada].

4. Cuántos niños asisten, por término medio.

5. Cómo podría mejorarse la asistencia.

6. Si en el desempeño de sus funciones, encuentra $\mathrm{Ud}$. obstáculos y cuáles son.

7. Qué apoyo le brindan las autoridades, el clero y los padres de familia.

8. Qué enseñanza ha dado Ud. hasta hoy, y con qué extensión.

Espero de Ud. este informe, sin el cual se me hace un tanto difícil adoptar resoluciones adecuadas para el rápido progreso de la enseñanza en ese plantel. ${ }^{43}$

Fue muy significativo que Dubarry se dirigiera personalmente a los directores, cuando bien pudo haberse dirigido a los gobernadores, como la tradición indicaba. Pero al nuevo Gobierno le interesaba tener información de primera mano. De ahí que en julio de aquél mismo año, además del Inspector General, el país contaba con tres subinspectores: uno destacado en la zona occidental, otro para la zona central y un tercero para el oriente del país. Posteriormente, el artículo 26 del nuevo reglamento (1889) estableció que:

En cada dos departamentos habrá un Inspector de Escuelas nombrado por el Poder Ejecutivo, que será el delegado inmediato del Director General, en las atribuciones y deberes correspondientes á este funcionario.

Y entre las obligaciones de los inspectores estarían:

... Visitar por lo menos tres veces al año, de la manera más minuciosa, todas las escuelas públicas y privadas de uno y otro sexo de cada una de las ciudades, pueblos, valles ó caseríos de su respectiva Sección.

...Dar al Director General, un informe minucioso y claro del estado de las escuelas de su Sección, de los inconvenientes que note y de las reformas que crea conveniente hacer, por lo menos tres veces en el año, es decir, cada vez que concluya la visita... ${ }^{44}$ 
Las Juntas y las Comisiones no desaparecieron, se transformaron. Las primeras pasaron a llamarse Juntas de Educación y a su pequeña composición (el Gobernador y su Secretario) se sumarían dos personas de reconocida honorabilidad, nombradas por el Ministerio de Instrucción Pública, y también se incorporaría el inspector departamental, en calidad de "miembro consultivo". Las Comisiones pasaron a llamarse Comisiones de Educación y estarían compuestas por el "Alcalde respectivo y de dos personas de lo más notable por su ilustración y amor á la enseñanza pública, de los respectivos distritos y pueblos, nombradas éstas por las Juntas de Educación del departamento".$^{45} \mathrm{El}$ orden jerárquico entre ambas instituciones se conservó: las Juntas estarían por encima de las Comisiones. Las Juntas continuaron conservando el poder de nombrar a los directores de escuelas. Pero el aumento de inspectores, delegados inmediatos del Director General, significaba que el Gobierno Central se acercaba cada vez más a lo local. De hecho, una de las obligaciones de los directores de escuelas consistiría en: "Informar mensual- mente al Inspector respectivo sobre el estado de adelanto en que se encuentre la escuela, lo mismo que sobre los inconvenientes y dificultades que se le presenten, para que éste esté al corriente de todo lo que ocurra en las escuelas de su Sección". ${ }^{46}$ Además, la medida de ampliar el número de inspectores no se quedó en el papel. Ya para el año 1890 el Gobierno reportó un total de siete de aquellos funcionarios. El cuadro 4 muestra el número de inspectores y el número de escuelas que estaban bajo su supervisión.

\subsection{Revista La Nueva Enseñanza: promotora de la nueva educación}

Los reformadores salvadoreños sabían muy bien de la importancia de contar con un órgano oficial que respondiera a la necesidad de difundir el nuevo imaginario educativo-pedagógico. Así, una de las principales novedades de la reforma fue la creación de la revista La Nueva Enseñanza. Su redactor, Víctor Dubarry, tuvo muy claro desde el principio cuál sería la finalidad de la revista. Así lo hizo saber:

Deseaba de tiempo atrás el Poder Ejecutivo de la República, organizar perfectamente la instrucción primaria; deseaba completar en la escuela por la enseñanza, la regeneración que en los campos de batalla había iniciado con las armas... Nosotros hemos sido llamados á colaborar en la alta empresa de la instrucción popular; y aún cuando carecemos de fuerzas poderosas, hemos aceptado... En las páginas de esta Revista procuraremos reunir los mejores y más moder- 
nos datos sobre sistemas de enseñanza; los textos más bien recibidos y aceptados en otros países; las noticias referentes a las reformas que aquí se establezcan y a los progresos que aquí se alcancen; y pasando de lo puramente didáctico y oficial, a la región del arte y de la ciencia, procuraremos también presentar muestras de lo que han escrito y escriben grandes pensadores y eminentes moralistas... La enseñanza moderna, progresiva en sus medios y filosófica en sus fines, tendrá en nosotros convencidos defensores. ${ }^{47}$

En efecto, desde mayo de 1887 hasta junio de 1890, salvo algunas interrupciones, la revista no defraudó con lo que había prometido. En La Nueva Enseñanza se publicaron lecciones de física, astronomía, geografía, cálculo oral, economía práctica, lectura y escritura, ciencia y literatura, ejercicios de gramática, piezas de literatura y, por supuesto, las infaltables lecciones objetivas o de objetos. También aparecieron lecciones de pedagogía para los docentes. En la sección "Variedades" se publicaron temas de diversa índole; en la sección "Crónica", noticias sobre los avances de la reforma. A partir de 1888 se dieron a conocer informes sobre las entregas de útiles y libros a las escuelas e informes de los inspectores de escuelas. En términos generales, dicha revista formó parte de ese "espacio público moderno" que permitió el debate de ideas, la presentación de los logros alcanzados por parte del Estado y la fiscalización de prácticas y procesos por parte de la ciudadanía que tenía acceso a esos espacios de discusión. ${ }^{48}$

\subsection{Hacia un nuevo método de enseñanza}

Sin embargo, el inspector Rengifo Núñez todavía se lamentaba, en mayo de 1887, que "la escuela no era el foco luminoso de los pueblos donde se encendía el pensamiento de las generaciones, se formaban hombres razonadores, independientes, dueños de sus acciones, sinó ciegos repetidores, cotorras sin sentido, cuyo ruido de palabras dejaba sólo cansancio nocivo y fatiga abrumadora en el espíritu de los niños". ${ }^{49}$

Ante ese error, el nuevo método de enseñanza, fundamentado en la pedagogía pestalozziana y fröbeliana, buscaba principalmente que el alumno aprendiera a través de la observación, descripción, análisis y, en el mejor de los casos, experimentación de los objetos de estudio. ${ }^{50}$ De ahí la razón de ser de aquella asignatura, Enseñanza Objetiva. Era tarea indispensable de los maestros, por lo tanto, despertar los sentidos del alumno, de manera que 
éste aprendiese a captar mejor el mundo circundante. Este principio pedagógico estaba fundamentado en otro de carácter más general: la enseñanza primaria debe adecuarse al desenvolvimiento natural del niño durante sus primeros años de vida. Ese crecimiento natural demuestra que en la infancia el ser humano aprende, fundamentalmente, a través de la captación del mundo por los sentidos. Por eso es que el método de educación primaria debía priorizar la enseñanza a través de la observación, descripción y análisis de los objetos de aprendizaje.
Francisco Esteban Galindo, por ejemplo, clasificaba los métodos de enseñanza en dos tipos: métodos de observación y métodos racionales. A criterio del autor, el segundo tipo era apropiado para la enseñanza secundaria y superior, pues la persona estaba ya en capacidad de comprender los razonamientos lógico-científicos que explicaban los fenómenos que se estudiaban; mientras que el método de observación, también denominado intuitivo, en honor a Pestalozzi, era el más apropiado para la educación de los primeros años. Así lo explicaba Galindo:

El método intuitivo, consiste en presentar al alumno las cosas sobre que versa la enseñanza para que las conozca, las analice, las describa por sus caracteres más notables y aprenda sus aplicaciones diversas.

... El niño en los primeros tiempos se instruye únicamente por las intuiciones que recibe. Sus primeras ideas sobre cosas, formas, colores, toda esa extensa serie de conocimientos con que se enriquece en poco tiempo el cerebro del recién venido á la vida, penetra en su alma por las intuiciones. Fue Enrique Pestalozzi el inventor de la enseñanza intuitiva y su influencia en la Pedagogía es comparable á la de Kepler en la ciencia astronómica.

... El Maestro... se empeñará en reunir en la Escuela una buena colección de objetos, y de cuadros murales de ilustraciones pictóricas. No es necesario que esas colecciones contengan cosas raras; por el contrario: lo que importa es que los niños aprendan á sacar partido de las cosas comunes, á usarlas, á combinarlas, á emplearlas; los muebles de la Escuela, las piedras de la calle, las plantas del jardín ó del patio, los granos cosechados, todo, absolutamente todo se presta á ser materia de una colección objetiva. ${ }^{51}$ 
La clave de la nueva educación estaba en saber encauzar el aprendizaje del educando mediante la observación del mundo, de manera que el niño y la niña desarrollaran la curiosidad investigativa antes de memorizar cualquier contenido, formula o idea. El libro que ganó el segundo lugar del concurso de obras de pedagogía, De la organización de la instrucción primaria en El Salvador, secundaba también los principios pedagógicos defendidos por Galindo:

... es necesario saber aprovechar y despertar en los niños el espíritu de observación á favor de sus facultades perceptivas, y solo el maestro imbuido en estos principios puede acostumbrarse á analizar los hechos; los fenómenos que se efectúen á su vista; hará fijar la atención en todas las cosas que tienen cerca de sí, presentando así una ancha base que el maestro debe aprovechar para ensanchar las demás facultades, que debe ser el objetivo de todo desarrollo intelectual. Esto es lo que se logra con la enseñanza objetiva y oral...

Los sentidos del niño son como las placas de una máquina fotográfica destinadas á recibir las impresiones de la luz. En el niño la curiosidad es un instinto que le lleva al deseo de observarlo todo. En las escuelas alemanas se aprovecha esta facultad para fijar el espíritu de observación y de atención procediendo de las ideas simples al desenvolvimiento de nociones mas completas sobre las cualidades y usos de los cuerpos. $^{52}$

La idea central del nuevo método de enseñanza era que el niño iría avanzando en su aprendizaje de lo conocido a lo desconocido, de lo empírico a lo abstracto, de lo simple a lo complejo. Se trataba de un aprendizaje progresivo.

Ciertamente, el tradicional método lancasteriano operaba con una noción de progresividad en el estudio. Una asignatura como Doctrina Cristiana podría dividirse en varias "Clases" o "niveles". Así, dicha asignatura, como cualquier otra, podía llegar a tener tres "clases": en la primera, podían ubicarse aquellos niños que leían ya el catecismo; en la segunda, los niños que lo leían de corrido; y en la tercera, aquellos que lo recitaban de memoria. Era un esquema de aprendizaje que se regía, principalmente, por la memorización de contenidos. Por eso Rengifo Núñez denunciaba que con ese método se formaban "ciegos repetidores" y "cotorras sin sentido". Poco importaba, podríamos decir, la psicología de aprendizaje del niño. 
Por el contrario, el nuevo método de enseñanza no solamente partía de la observación científica del modo a través del cual los niños aprehenden el mundo en los primeros años de vida, sino que, en buena medida, hacía del niño el centro del proceso de enseñanzaaprendizaje. La idea consistía en que el alumno lograra comprender qué era un objeto o cosa por medio de la observación, descripción y análisis de sus cualidades, funciones y modo de ser propio. De ahí el nombre de enseñanza objetiva. Se le apostaba al aprendizaje que po- nía a los niños en contacto con las cosas o con aquello (una imagen, un grabado o un dibujo) que las representaba. Por supuesto, esta forma de conceptuar la enseñanza no solo se aplicó en El Salvador. Dicho método se hizo presente en prácticamente toda América Hispana.

Por supuesto, esa nueva educación no se lograría mientras los docentes no mejoraran su práctica pedagógica en función del nuevo método. Fue así que, volviendo al caso salvadoreño, Núñez enfatizó en lo siguiente:

Señores: - Fijados los principios sobre que descansa la enseñanza sistemática y metódica, importa sobre manera, que los procedimientos sean claros y adecuados para facilitar la evolución natural del espíritu. No basta saber que en la instrucción primaria - para alcanzar un éxito feliz- se procederá siempre de los empírico á lo racional, de lo concreto á lo abstracto, de lo simple á lo compuesto, de lo definido á lo indefinido, de lo conocido á lo desconocido, etc.

Es preciso también que el profesor tenga sumo cuidado en los menos detalles de aplicación práctica, tanto para dirigir sus clases con perfecto orden, buena disciplina y provecho, como para asegurar los grandes resultados que se proponga obtener en cada uno de los diversos ramos que constituyen el programa enseñanza. ${ }^{53}$

Dos meses después, la revista La Nueva Enseñanza volvía a insistir en la importancia de que los maestros se prepararan para poner en práctica la nueva educación que el Gobierno estaba implementando. En la enseñanza, el maestro debía regirse por siete leyes:

1. Conocer á fondo lo que se ha de enseñar. 2. Lograr y sostener la atención e interés de los discípulos. 3. Usar un lenguaje que los discípulos puedan entender bien, y explicar con claridad el significado de toda palabra nueva que 
sea necesaria. 4. Empezar por lo ya conocido, y pasar á lo desconocido, por grados, natural y fácilmente. 5. Excitar la actividad intelectual de los discípulos, y llevarlos á descubrir por sí mismos la verdad. 6. Exigir que los discípulos expongan completa y correctamente, en su propio lenguaje, las verdades que se les hayan enseñado, debiendo afirmarlas con pruebas y ejemplos. 7. Dar muchos pasos á cada asunto con todo cuidado y detenimiento, y agregando nuevas ideas que confirmen las ya conocidas. Estas leyes sustentan y gobierna toda enseñanza eficaz. ${ }^{54}$

Es importante señalar también que estamos frente a una época en la que la enseñanza se conceptúa ya como una ciencia, cuyo nombre es pedagogía. El 15 de junio de 1888, La Nueva Enseñanza definía este saber científico en los siguientes términos:

\section{1. - Pedagogía es la ciencia que estudia los principios en} que se funda la perfección física y moral del hombre y que enseña al mismo tiempo, en virtud de esos mismos principios, á trasmitir los conocimientos con claridad y prontitud. Pedagogía es, pues, la ciencia de la educación.

2. - Como ciencia trata de qué, cuándo y por qué se debe enseñar para obtener el desarrollo armónico tanto del cuerpo como del alma; y como arte se ocupa únicamente en el cómo se debe exponer á los escolares lo que se les ha de trasmitir.

3. - La Pedagogía, como ciencia de la Educación cuida, pues, tanto del cuerpo como del espíritu; y no puede desatender á ninguna de las partes que éstos comprenden, porque, si de cada una de ellas no cuidara, no cumpliría con su objeto y el sér humano podría verse expuesto, en lo futuro, á los contratiempos que casi siempre origina una educación imperfecta. ${ }^{55}$

No obstante, puede apreciarse que en realidad la pedagogía se conceptuaba a la vez como ciencia y arte. En calidad de ciencia, "trata de qué, cuándo y por qué" se debe enseñar. Como arte, "se ocupa únicamente en el cómo" se ha de ejecutar la enseñanza. En términos generales, a fines del siglo XIX en Hispanoamérica el discurso pedagógico fue tomando un rostro marcadamente científico. Entre 
otras cosas, se generó una profunda preocupación por las condiciones ambientales en las que debía aprender el niño, la higiene y salubridad del cuerpo del escolar, la adecuada alimentación del infante como principio del buen aprendizaje, la práctica de la gimnasia, el orden y la limpieza en el salón de clases, el perfeccionamiento de la estadística en el control de las escuelas, etc. En otras palabras, el proceso de enseñanza-aprendizaje fue sometido a una rigurosa observación científi$\mathrm{ca}$, a manera de dar con los mejores procedimientos para lograr una mejor educación y hacer más accesible el ansiado progreso. Por último, hay que decir que no sólo el método de enseñanza estaba cambiando, sino también la concepción misma del sujeto que debía educarse. El discurso pedagógico de la reforma muestra que no sólo se trató de un cambio en el cómo enseñar, sino, también, en el a quién enseñar. Se dio, pues, un cambio en la visión antropológica del educando.

\subsection{Una nueva visión antropológica}

En el discurso educativo de la reforma se impuso un concepto integral de ser humano. En lo esencial, se planteó que el alumno es un ser con tres facultades a las que se debe educar en igual proporción: moral, intelectual y física. La educación debía procurar el equilibrio de esas tres dimensiones del ser humano. Hay material abundante para desarrollar este apartado. No obstante, voy a ceñirme al libro Elementos de pedagogía de Francisco Esteban Galindo. Comencemos, por tanto, con la descripción de esas tres facultades por parte de Galindo:

Educar es mejorar al hombre, dirigiendo bien y desarroIlando armónicamente sus facultades. La educación se divide en física, intelectual y moral. La primera tiene por objeto desarrollar, vigorizar y perfeccionar el organismo. La segunda habitúa á la observación y á la atención, da exactitud al raciocinio y enriquece y desarrolla todas las facultades intelectuales. La tercera forma el carácter, dirige las pasiones y habitúa á la práctica Moral. Instruir es enseñar conocimientos útiles. Puede haber educación sin instrucción; pero la instrucción es á la vez objeto y medio general de educación. ${ }^{56}$

La clave de la educación está en desarrollar armónicamente las tres facultades del educando, para ello es indispensable la instrucción como medio para enseñar aquellos conocimientos considerados útiles por la sociedad. Pero la educación no se agota en la instrucción. Por eso dice Galindo que "la instrucción á veces llega á perderse; pero 
la educación que ella ha proporcionado es permanente" ${ }^{\prime 57} \mathrm{Y}$ da un ejemplo al respecto: "A un niño que sepa las reglas fundamentales de la Aritmética se le puede educar más y más el raciocinio, obligándole á hacer cálculos mentales, sin darle por esto una sola idea más de las que ya tiene. Lo mismo puede decirse de las demás facultades" ${ }^{58} \mathrm{La}$ educación, en tal sentido, tiene que ver con la aprehensión por parte del alumno de unos modos necesarios para enfrentar, comprender, manejar y resolver las cosas que el mundo pone a su paso; mientras que la instrucción tiene que ver directa y específicamente con la adquisición de saberes o conocimientos. Instruir es proveer conocimientos; educar es preparar para la vida. Así lo estableció en el artículo 31 el nuevo reglamento de educación primaria (1889):

Las escuelas primarias tienen por objeto preparar á los individuos que á ellas concurran, en lo físico, intelectual y moral para todos los asuntos inherentes á la vida independiente y práctica, y en una palabra, propender á la felicidad de ellos; de donde se deduce que la enseñanza que en las escuelas se dé, no debe tender á la instrucción ó parte intelectual solamente, sino á la educación ó perfeccionamiento completo del educando. ${ }^{59}$

De acuerdo al ejemplo proporcionado por Galindo, con el ejercitamiento del raciocinio a partir de las reglas fundamentales de la Aritmética se buscaba que el niño perfeccionara su capacidad para resolver en forma matemática diversos problemas que la realidad le presentara. No se le da "una sola idea más de las que ya tiene", dice el autor; pero se le prepara (educa) mejor en el manejo de los razonamiento matemáticos. Esta lógica de enseñanza era aplicable a la educación de las tres facultades del individuo: intelectual, física y moral. Sinteticemos a continuación las características principales de la educación de cada una de las facultades.
Tres objetivos comprende la educación física: "el desarrollo del cuerpo y de las fuerzas musculares", "el hábito de moderación en la satisfacción de las necesidades físicas" y "el perfeccionamiento de los sentidos". El objetivo principal consistirá en moldear el cuerpo del niño. La escuela se concibe como ese aparato moderno de disciplinamiento mediante el cual serán sometidas las fuerzas del cuerpo con el objetivo de crear una sociedad de individuos ágiles, vigorosos, útiles e higiénicos. Esta educación tiene tres componentes fundamentales: la buena alimentación por parte del educando, la educación de los sentidos en el salón de clases y los ejercicios en las escuelas, vía gim- 
nasia, calistenia, ejercicios militares (para los niños) o labores de mano (para las niñas).

En cuanto a la educación intelectual —segunda en el orden de exposición del autor-, afirma que ésta tiene por objeto: "el desarrollo de las facultades intelectuales", "poner al hombre en aptitud de dirigirse y de encontrar verdades por sí mismo" y "darle la instrucción necesaria para que cumpla fácilmente su destino". Al mismo tiempo aclara que cuatro son las facultades intelectuales: la percepción, la memoria, la imaginación y el entendimiento. Por la percepción, el individuo recibe las sensaciones que le transmiten los sentidos; por la memoria, se recuerdan las ideas; mediante la imaginación se combinan y transforman las ideas dadas por la percepción; $y$, finalmente, por medio del entendimiento se juzga y razona. Pero el entendimiento en sentido estricto posee dos dimensiones: juicio y raciocinio. $\mathrm{El}$ juicio permite comparar las ideas y mediante el razonamiento inferimos unas ideas de otras.

Galindo insistirá en que la buena educación debe atender siempre las tres facultades en su conjunto, en un modo equilibrado y gradual. Cuando el maestro prioriza una facultad por encima de las otras, entonces la educación se deforma, es decir, se deforma al individuo. Por supuesto, como ya lo analizamos en el apartado anterior, el autor reconoce que en los primeros años la facultad que predomina en el niño es la percepción, de ahí que el resto de facultades deben formarse en función de aquella. Sólo el desarrollo integral de estas facultades de la inteligencia podía crear un individuo bien instruido, capaz de hacer avanzar el progreso de la sociedad con la aplicación de aquellos conocimientos que sean necesarios. Puede apreciarse nuevamente la propuesta de una educación según un plan pedagógico bien definido; es decir, según sea el crecimiento del infante, así se le irá instruyendo en el aprendizaje de los conocimientos científicos. Lo importante no es perder de vista la formación integral de sus facultades intelectuales.

Como el resto de facultades, la educación moral tiene también tres objetivos: "Crear hábitos de moderación para la satisfacción de las necesidades, "someter la voluntad al deber" y "sembrar en el corazón los gérmenes de la virtud". Según Galindo, el hombre está abocado a satisfacer sus esenciales necesidades, pero éstas pueden conducirlo al desbocamiento de las pasiones, es decir, a ser desmedido y, por tanto, a grajearse su propia perdición.

El hombre tiene necesidades; las necesidades engendran los deseos; los deseos determinan la voluntad, y cuando la voluntad es vehemente, constituye una pasión. Una pasión, 
pues, es una necesidad sentida con vehemencia, ó como dice Descuret, es la tiranía de una necesidad. A veces se designa también la necesidad con la palabra pasión.

(...) Las necesidades son esencialmente buenas; ellas son las velas de la humanidad. Satisfacerlas es un deber; exagerar esta satisfacción fuera de los límites racionales ó desatenderlas, es lo que se llama una pasión. Así es que toda necesidad es el germen de una virtud y de un vicio. La virtud está en el término medio y por eso la prudencia debe reglar nuestros actos. ${ }^{60}$

Como puede apreciarse, el planteamiento del término medio que hace Galindo tiene mucho parecido con el justo medio aristotélico; no obstante, por la referencia que hace al médico francés Jean Baptiste Félix Descuret (17951871), todo parece indicar que el análisis de las pasiones lo extrae del libro La medicina de las pasiones. ${ }^{61}$ Las pasiones primero piden, luego exigen $y$, finalmente, obligan; de ahí que el objetivo fundamental del maestro es lograr que el niño se encauce en una vida virtuosa. Las pasiones pueden combatirse por desviación, haciéndolas cambiar de objeto, o por oposición, contraponiéndoles otro tipo de pasiones. De ahí que cuando el profesor identifique alguna pasión predominante en el niño, procurará corregirla ya sea por desviación o por oposición. Pero no debían emplearse castigos que atentaran contra la dignidad del niño; el educador debía dar a los niños nociones claras de lo que es el bien y el mal, así ellos sabrían conducirse en la vida por los caminos del bien: "Es un error creer que los castigos severos educan; engendran el miedo, pasión vil que, opuesta á las otras, á veces las vence; pero que siempre debilita el carácter y cuya acción es transitoria. El niño severamente castigado llegará á ser hombre y á verse libre del castigo; entonces cesará la oposición, y las pasiones mal vencidas levantarán de nuevo la cabeza". ${ }^{62}$ David J. Guzmán secunda las ideas de Galindo: "Y si tan grandes resultados puede dar á la sociedad el incentivo de las instrucción no menos provechosos son para el individuo particularmente. Entre estas ventajas cuéntase en primer lugar la morigeración de las pasiones sociales, la represión de los vicios" ${ }^{63}$ En definitiva, sólo sabiendo conjugar la adecuada formación del intelecto, la disciplina diaria de los ejercicios y la educación para una vida virtuosa podía establecerse una educación altamente eficiente, es decir, capaz de lograr esa mejoría que se proponía la educación en general. 
Cuando los gobiernos pretenden lograr transformaciones a largo plazo en la sociedad, deciden echar a andar reformas que, por lo general, tocan puntos medulares de la población. Ese fue el caso de la reforma educativa que hemos estudiado. Los reformadores de la escuela salvadoreña tenían la convicción de que reformando el sistema educativo en su conjunto no sólo lograrían forjar una nueva mentalidad en los futuros ciudadanos, sino también abrir los espacios necesarios para construir una sociedad abierta, diversa y secular.

Al mismo tiempo, es importante destacar que se trató de una reforma educativa que, en lo fundamental, contó con el apoyo de, por lo menos, dos gobernantes: Zaldívar y Menéndez. Hecho del que se puede inferir que aquella novedosa reforma no fue el fruto de la imaginación caprichosa de un presidente; al contrario, bien podríamos decir que respondió a una visión de país, de nación. Más allá de las diferencias que pudieron existir entre los liberales radicales, podemos afirmar que en materia educativa defendieron un proyecto en común; aun cuando parece que a la caída de Menéndez — cuando ya las principales reformas secularizantes se habían logrado, por supuesto- la reforma perdió sostenibilidad y consistencia, pero esto será tema para una futura investigación. Por ahora, lo cierto es que buena parte de la estructura que actualmente tiene la educación pública básica se forjó en la década de 1880, específicamente con la reforma de los años 1887-1890.

Es cierto, hubo dificultades económicas; a la instrucción pública no siempre se le asignó una partida generosa. Pero a pesar de las carencias en materia financiera (tema también de otra investigación), lo cierto es que la innovación en prácticas e ideas educativo-pedagógicas, así como la eliminación del credo católico de las escuelas públicas, entre otras, fueron realidades culturales de enorme relevancia, cuya ignorancia nos impediría comprender (en su conjunto) las reformas liberales laicizantes y secularizantes de fines del siglo XIX. Aquella desconocida reforma nos enseña que la educación, en la medida en que se ha trazado la ardua tarea de formar a las nuevas generaciones, casi siempre tendrá que lidiar con similares problemas y/o preguntas: ¿qué enseñamos?, ¿cómo enseñamos?, ¿con qué?, y ¿a quiénes? 
1 Este artículo se ha elaborado a partir del capítulo tres de la siguiente tesis: Julián González Torres, Del «ciudadano católico» «al ciudadano laico». La escuela pública primaria y la formación de los futuros ciudadanos. El Salvador 1824-1890. Tesis presentada para optar al grado de Doctor en Filosofía Iberoamericana, Universidad Centroamericana "José Simeón Cañas”, Antiguo Cuscatlán, 2012. Para ampliar los conocimientos sobre esta reforma educativa, consúltese en: http://www.uca.edu.sv/filosofia/ admin/files/1341957152.pdf

2 Memoria de Instrucción Pública y Beneficencia, Imprenta Nacional del Dr. F. Sangrini, San Salvador, 1884, p. 3.

3 Manuel Luis Escamilla, Reformas educativas: Historia contemporánea de la educación formal en El Salvador, Dirección de Publicaciones del Ministerio de Educación, San Salvador, 1981, p. 44.

4 Lucía Lionetti, La misión política de la escuela pública: formar a los ciudadanos de la república (1870-1916), Miño y Dávila, Buenos Aires, 2007.

5 Gilberto Loaiza Cano, "El maestro de escuela o el ideal liberal de ciudadano en la reforma educativa de 1870", Historia Crítica, 34, Julio-Diciembre 2007, pp. 62-91.

6 Iván Molina Jiménez, "Educación y sociedad en Costa Rica: de 1821 al presente (una historia no autorizada)", Diálogos. Revista Electrónica de Historia, 2, Agosto 2007-Febrero 2008, pp. 151356.

7 Mílada Bazant, Historia de la educación durante el porfiriato, El Colegio de México, Centro de Estudios Históricos, México, D. F., 1993.
8 Olga Carolina Vásquez Monzón, "Sobre la instrucción intelectual de las mujeres en la prensa salvadoreña. "Hechos y decires", 1871-1887", Cultura. Revista de la Secretaría de Cultura de la Presidencia, 106, Abril-Junio 2011, pp. 27-53.

9 "Memoria de Instrucción Pública y Beneficencia", Diario Oficial, 68, Viernes 19 de Marzo de 1880, p. 276.

10 De acuerdo al reglamento de instrucción primaria decretado en 1873 , dicho ramo tendría tres fuentes de financiamiento: (1) la cantidad que anualmente designara el Cuerpo Legislativo; (2) los sobrantes de los fondos de las municipalidades, así como los fondos que originariamente se destinaran a tal fin; (3) la contribución de los padres de familia. Este último fondo se obtendría de la siguiente manera: En las poblaciones donde faltaren escuelas por escasez total o parcial de fondos, los padres de familia darían una contribución directa de uno a cuatro reales al mes. La contribución correría por cuenta de aquellos padres que tuviesen hijos de entre siete y quince años, los cuales no tuviesen ningún inconveniente legal para asistir a la escuela; también contribuirían aquellos padres cuyos niños sin haber cumplido la edad indicada, ya asistiesen a la escuela.

11 Memoria de Instrucción Pública y Beneficencia, 1884, p. 4. Las cursivas son mías.

12 "Memoria de Instrucción Pública y Beneficencia", Diario Oficial, 58, Jueves 9 de Marzo de 1882, p. 238.

13 "Memoria de Instrucción Pública y Beneficencia", Diario Oficial, 68, Viernes 19 de Marzo de 1880, p. 276.

14 Memoria de Instrucción Pública y Beneficencia, 1884, p. 34. 

coles 25 de mayo de 1881, p. 517.

16 Memoria de Instrucción Pública y Beneficencia, 1884, p. 3. Las cursivas son mías.

17 Miguel Ángel Gallardo (Recopilador), Cuatro constituciones federales de Centro América y las constituciones políticas de El Salvador, Tipografía La Unión, San Salvador, 1945, p. 188. El Estado salvadoreño, según la misma Constitución, contaba con tres poderes: Ejecutivo, Judicial y Legislativo. Éste último era ejercido por dos Cámaras: una de Diputados y otra de Senadores.

18 "Vigésima novena sesión de la Cámara de Senadores, celebrada el día nueve de Febrero de mil ochocientos ochenta y tres", Diario Oficial, 40, Viernes 16 de Febrero de 1883, p. 158.

19 "Ministerio de Instrucción pública", Diario Oficial, 55, Martes 6 de Marzo de 1883, p. 233.

20 Antonio Acosta, "Hacienda y finanzas de un Estado oligárquico. El Salvador, 1874-1890”, en Pilar García Jordán (Ed.), Estado, región y poder local en América Latina, Siglos XIX-XX, Publicacions i edicions de la Universitat de Barcelona, Barcelona, 2007, pp. 55-63.

21 "Cartera de Instrucción Pública", Diario Oficial, 123, Martes 1 de Junio de 1886, p. 590 .

22 James Bowen, Historia de la educación occidental. Tomo III: El occidente moderno, Europa y el Nuevo Mundo, Siglos XVII-XX, Herder, Barcelona, 1992, pp. 424-425; Samuel Eliot Morison, Henry Steele Commager, William E. Leuchtenburg, Breve historia de los Estados Unidos, Fondo de Cultura Económica, México, D. F., 1999, p. 536.

23 Olga Lucía Zuluaga G., "Entre Lancaster y Pestalozzi: los manuales para la formación de maestros en Colombia, 1822-1868", Revista de Educación y Pedagogía, 29-30, Enero-Septiembre 2001, pp. 41-49; Luis Alarcón Meneses, Jorge Conde Calderón, Adriana Santos Delgado, "La cuestión de los métodos pedagógicos en el estado soberano del Magdalena: un discurso modernizador", en VIII Anuario de Historia Regional y de las Fronteras, Escuela de HistoriaUniversidad Industrial de Santander, Bucaramanga, 2002, pp. 123-244.

24 Iván Molina Jiménez, "Educación y sociedad en Costa Rica: de 1821 al presente..."; Astrid Fischel Volio, "La educación costarricense: entre el liberalismo y el intervencionismo", en Jorge Mario Salazar Mora (Ed.), Historia de la educación costarricense, Universidad Estatal a Distancia, Universidad de Costa Rica, San José, 2003, pp. 73-115.

25 María de los Ángeles Rodríguez Álvarez, Sara Griselda Martínez Covarrubias, "En el umbral de la pedagogía mexicana. José Manuel Guillé 1845-1886”, Revista Mexicana de Investigación Educativa, 26, Julio-Septiembre 2005, pp. 931-950.

26 Jorge Gustavo Araujo, La Iglesia católica salvadoreña y la laicización de la educación en 1881: ¿Un proyecto liberal frente a una respuesta ultramontana?, Tesis presentada para optar al grado de Maestro en Filosofía Iberoamericana, Universidad Centroamericana "José Simeón Cañas", San Salvador, 2009.

27 Roberto Armando Valdés Valle, Masones, liberales y ultramontanos salvadoreños: debate politico y constitucional en algunas publicaciones impresas, durante la etapa final del proceso de secularización del Estado salvadoreño (1885-1886), tesis presentada para optar al grado de Doctor en Filosofía Iberoamericana, Universidad Centroamericana "José Simeón Cañas", San Salvador, 2010, pp. 185-242. 
28 "Instrucción pública", Diario Oficial, 153, Viernes 3 de Julio de 1885, pp. $9-10$.

29 Jorge Alfaro Jovel, "Reseña de la evolución histórica de la escuela primaria en El Salvador", Revista del Ministerio de Instrucción Pública, 10, Octubre-NoviembreDiciembre, 1940, pp. 3-23.

30 "Instrucción pública", Diario Oficial, 153, Viernes 3 de Julio de 1885, p. 11.

31 El artículo 92 del nuevo reglamento establecía lo siguiente: "Se entiende por Primer Grado, el de los alumnos que principian ó no saben nada; por segundo, el de los que tienen un año de enseñanza y saben las materias del primero, según programa; por tercero, el de los que tienen dos y saben las materias del segundo etc.; y así sucesivamente". "Reglamento de Educación Pública Primaria", Diario Oficial, 136, Martes 11 de junio de 1889.

32 El reglamento definió así las escuelas rurales: "Art. 12. - Por Escuelas Rurales se comprende todas aquellas de los caseríos que, por su distancia de más de dos kilómetros de los centros poblados, se funden como para completar el cuadro de la enseñanza pública en todo el territorio nacional". Dicho tipo de escuela se regiría por los mismos principios académico-administrativos de las escuelas elementales.

33 En principio, San Salvador y La Libertad contaban también con sus respectivas escuelas superiores; lo que sucede es que no se ha encontrado una fuente que confirme su existencia, así como el número de matriculados.

34 "Memoria de Instrucción Pública", Diario Oficial, 91, Jueves 21 de Abril de 1887, p. 469.

35 Ibid
36 Margarita Silva Prada, "La enseñanza de la historia en el sistema educativo salvadoreño", Cultura. Revista del Consejo Nacional para la Cultura y el Arte, 93, 2006, pp. 35-51.

37 M. Víctor Duruy, Historia sagrada según la Biblia, Librería Hachette y Compañía, París, 1880, p. X.

38 Pedro Flores, "INFORME que el infrascrito Director de la Escuela Primaria de niños del barrio de Remedios... acerca del estado general en que al terminar sus tareas escolares se encuentran los alumnos de la misma", Diario Oficial, 296, Sábado 25 de Diciembre de 1886, p. 1375. Las cursivas son mías.

39 La materia Historia Sagrada fue suprimida del currículo en enero de 1894 , bajo la presidencia de Carlos Ezeta (1890-1894), quien ese mismo año sería derrocado por Rafael Antonio Gutiérrez, quien gobernó en el período 1894-1898. "Secretaría de Instrucción Pública y Beneficencia. Cartera de Instrucción Pública", Diario Oficial, 12, Sábado 13 de enero de 1894, p. 45.

40 La Comisión de vigilancia estaba compuesta por el Alcalde, un Regidor y el Secretario municipal. La Junta departamental, por su lado, estaba compuesta por el Gobernador y su Secretario.

41 "Copia del primer reglamento completo de Instrucción Pública decretado en El Salvador en el año de 1873", Revista del Departamento de Historia y Hemeroteca Nacional, 3, Agosto de 1939, p. 94.

42 Ibid., pp. 86, 94, 97 y 98.

43 La Nueva Enseñanza, 1, Mayo 14 de 1887, pp. 24-25.

44 "Reglamento de Educación Pública Primaria", Diario Oficial, 136, Martes 11 de junio de 1889, p. 699.

45 Ibid., p. 697. 
46 Ibid., p. 702.

47 "Ideas y propósitos", La Nueva Enseñanza, 1, Mayo 14 de 1887, pp. 1 у 3.

48 Sajid Alfredo Herrera, "Prensa y formación de un espacio público moderno: la Provincia/Estado del Salvador, 1810-1890", en Carlos Gregorio López Bernal (Comp.), Poder, actores sociales y conflictividad. El Salvador, 1786-1972, Dirección Nacional de Investigaciones en Cultura y Arte, Secretaría de Cultura de la Presidencia, San Salvador, 2011, pp. 101-130.

49 Rengifo Núñez, "Conferencias pedagógicas”, La Nueva Enseñanza, 1, 1887, p. 4.

50 Para una noción general de lo que fue la pedagogía pestalozziana y fröbeliana, véanse: Johann Heinrich Pestalozzi, Cartas sobre educación infantil, Tecnos, Madrid, 1996; Federico Fröbel, La educación del hombre, D. Appleton y Compañía, Nueva York, 1902; José Manuel Villalpando, Historia de la educación y de la pedagogía, Porrúa, México D.F., 2000; James Bowen, Historia de la educación occidental. Tomo III...; Georges Piaton, Pestalozzi: La confianza en el ser humano, Trillas, México D.F., 1989; N. Abbagnano, A. Visalberghi, Historia de la pedagogía, Fondo de Cultura Económica, México, 1964.

51 Francisco Esteban Galindo, Elementos de pedagogía, Imprenta Nacional, San Salvador, 1887, pp. 145, 150-151. Cursivas en el original.

52 David J. Guzmán, De la organización de la instrucción primaria en El Salvador, Imprenta Nacional, San Salvador, 1886, pp. $49,82$.
53 Rengifo Núñez, "Conferencias pedagógicas”, La Nueva Enseñanza, 2, Junio 12 de 1887, pp. 6-7.

54 "Indicaciones útiles a los maestros. I. LAS SIETE LEYES DE LA ENSEÑANZA (Gregory)", La Nueva Enseñanza, 4, Agosto 31 de 1887, p. 5. La cita fue tomada del libro Las siete leyes de la enseñanza, del estadounidense John Milton Gregory (1822-1898). En 1858 fue nombrado Superintendente de Instrucción Pública en el Estado de Michigan. Su libro se publicó por primera vez en 1884 .

55 "Guía para las escuelas del Salvador. PRELIMINARES”, La Nueva Enseñanza, 5, Junio 15 de 1888, p. 1.

56 Francisco Esteban Galindo, Elementos de pedagogía, p. 3.

57 Ibid., p. 4.

58 Ibid., p. 5.

59 "Reglamento de Educación Pública Primaria", Diario Oficial, 136, Martes 11 de junio de 1889, p. 699.

60 Francisco Esteban Galindo, Elementos de pedagogía, pp. 21-22. Cursivas en el original.

61 Jean Baptiste Félix Descuret, La medicina de las pasiones ó las pasiones consideradas con respecto a las enfermedades, a las leyes y a la religión, Imprenta y Librería de Pablo Riera, Barcelona, 1857.

62 Francisco Esteban Galindo, Elementos de pedagogía, p. 26.

63 David J. Guzmán, De la organización de la instrucción primaria..., p. 8. 


\begin{tabular}{|c|c|c|c|}
\hline \multicolumn{4}{|c|}{$\begin{array}{c}\text { Cuadro 1: } \\
\text { Propuesta de Rafael Reyes para reformar el Sistema de Enseñanza Pública Primaria } \\
\text { PLAN DE ESTUDIOS DE ENSEÑANZA PRIMARIA }\end{array}$} \\
\hline & Escuelas de primera clase & Escuelas de segunda clase & Escuelas de tercera clase \\
\hline 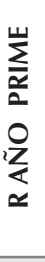 & $\begin{array}{l}\text { 1. Lectura. } \\
\text { 2. Gramática Castellana } \\
\text { (Analogía y Ortografía). } \\
\text { 3. Aritmética. } \\
\text { 4. Escritura. } \\
\text { 5. Lecciones sobre objetos. }\end{array}$ & $\begin{array}{l}\text { 1. Lectura. } \\
\text { 2. Gramática Castellana } \\
\text { (Analogía y Ortografía). } \\
\text { 3. Aritmética. } \\
\text { 4. Escritura. } \\
\text { 5. Escritura al dictado. }\end{array}$ & $\begin{array}{l}\text { 1. Lectura. } \\
\text { 2. Gramática Castellana } \\
\text { (Analogía). } \\
\text { 3. Aritmética. } \\
\text { 4. Escritura. } \\
\text { 5. Generalidades de } \\
\text { geografía. }\end{array}$ \\
\hline 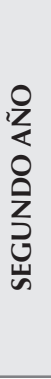 & $\begin{array}{l}\text { 1. Lectura. } \\
\text { 2. Escritura y Dibujo lineal. } \\
\text { 3. Escritura al dictado. } \\
\text { 4. Geografía astronómica y } \\
\quad \text { física. } \\
\text { 5. Gramática } \\
\text { (Sintaxis y prosodia). } \\
\text { 6. Historia. } \\
\text { 7. Lecciones sobre objetos. } \\
\text { 8. Moral y urbanidad. } \\
\text { 9. Aritmética. }\end{array}$ & $\begin{array}{l}\text { 1. Lectura. } \\
\text { 2. Escritura. } \\
\text { 3. Geografía de América, } \\
\text { especialmente de la } \\
\text { América del Centro. } \\
\text { 4. Gramática Castellana } \\
\text { (Sintaxis y prosodia). } \\
\text { 5. Generalidades de } \\
\text { Historia. } \\
\text { 6. Moral y Urbanidad. } \\
\text { 7. Aritmética. }\end{array}$ & $\begin{array}{l}\text { 1. Lectura. } \\
\text { 2. Escritura al dictado. } \\
\text { 3. Generalidades de } \\
\text { geografía. } \\
\text { 4. Gramática Castellana. } \\
\text { 5. Nociones de Historia } \\
\text { Natural. } \\
\text { 6. Moral y Urbanidad. } \\
\text { 7. Aritmética. }\end{array}$ \\
\hline 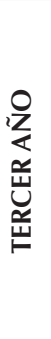 & $\begin{array}{l}\text { 1. Lectura. } \\
\text { 2. Escritura al dictado. } \\
\text { 3. Dibujo. } \\
\text { 4. Geografía Política. } \\
\text { 5. Historia. } \\
\text { 6. Moral y Urbanidad. } \\
\text { 7. Aritmética. } \\
\text { 8. Nociones de Algebra. } \\
\text { 9. Nociones de Física. } \\
\text { 10. Recitación. }\end{array}$ & $\begin{array}{l}\text { 1. Lectura. } \\
\text { 2. Escritura al dictado. } \\
\text { 3. Nociones de Historia } \\
\text { Natural. } \\
\text { 4. Nociones de Agricultura. } \\
\text { 5. Moral y Urbanidad. } \\
\text { 6. Aritmética. }\end{array}$ & \\
\hline
\end{tabular}

Fuente: "Instrucción Pública", Diario Oficial, 153, Viernes 3 Julio de 1885, p.10. 


\section{Primer Grado:}

Lectura, Caligrafía, Aritmética, Enseñanza Objetiva, Ejercicios militares y Canto.

$\S$ Si la escuela fuere de niñas tendrá en vez de la de Ejercicios militares la clase de Labores de mano, debiendo ser obligatoria en todos los grados, y ser enseñada por espacio de una hora diaria por lo menos.

\section{Segundo Grado:}

Lectura, Caligrafía, Aritmética, Enseñanza Objetiva, Canto, Geografía, Historia Sagrada y Gimnasia ó Calistenia.

$\S$ En las escuelas de varones es obligatoria además la clase de Ejercicios militares en todos los Grados.

\section{Tercer Grado:}

Lectura, Caligrafía, Aritmética, Enseñanza Objetiva, Canto, Geografía, Historia Sagrada, Gimnasia, Gramática Castellana, Geometría y Dibujo.

\section{Cuarto Grado:}

Lectura, Caligrafía, Aritmética, Canto, Geografía, Historia Sagrada, Gimnasia, Gramática Castellana, Geometría, Dibujo, Historia Patria y Elementos de Fisiología y Zoología.

$\S$ Si la escuela fuere de niñas, deberá tener en este grado, además, la clase de Economía Doméstica, para que sea continuada en el quinto y sexto.

\section{Quinto Grado:}

Lectura, Caligrafía, Aritmética, Canto, Geografía, Historia Sagrada, Gimnasia, Gramática Castellana, Geometría, Dibujo, Historia Patria, Fisiología, Zoología, Física, Cosmografía, Inglés y Educación Cívica ó Cartilla del Ciudadano.

\section{Sexto Grado:}

Lectura, Caligrafía, Aritmética, Canto, Gimnasia, Gramática Castellana, Dibujo, Zoología, Botánica, Física, Historia Patria, Cosmografía, Inglés, Francés, Historia Universal y Elementos de Agricultura.

Fuente: Elaboración propia a partir de: "Reglamento de Educación Pública Primaria", Diario Oficial, 136, Martes 11 de junio de 1889 . 


\begin{tabular}{|c|c|c|c|}
\hline 1832 & 1861 & 1873 & 1889 \\
\hline $\begin{array}{ll}\checkmark & \text { Lectura } \\
\checkmark & \text { Escritura } \\
\checkmark & \text { Principios de } \\
& \text { Aritmética } \\
\checkmark & \text { Principios de } \\
& \text { Moral } \\
\checkmark & \text { (Principios } \\
& \text { de la) } \\
& \text { Constitución } \\
\text { de la } \\
\text { República y } \\
\text { del Estado }\end{array}$ & $\begin{array}{ll}\checkmark & \text { Lectura } \\
\checkmark & \text { Escritura } \\
\checkmark & \text { Aritmética } \\
& \text { Práctica } \\
\checkmark & \text { Ortografía } \\
\checkmark & \text { Doctrina } \\
& \text { cristiana }\end{array}$ & \begin{tabular}{|ll} 
Escuelas Primarias \\
$\quad$ Elementales: \\
$\checkmark$ & Lectura \\
$\checkmark$ & Escritura \\
$\checkmark$ & Aritmética \\
& Elemental \\
$\checkmark$ & Elementos de \\
& Gramática \\
& Castellana \\
$\checkmark$ & Nociones \\
& Elementales de \\
& Geografía \\
$\checkmark$ & Religión y Moral \\
$\checkmark$ & La Cartilla del \\
& Ciudadano \\
$\checkmark$ & La Ley de Jurados \\
Escuelas Primarias \\
& Superiores (además \\
& de las materias \\
anteriores): & \\
$\checkmark$ & Elementos de \\
& Cosmografía y \\
& nociones sumarias \\
de Geografía Física & y Política \\
$\checkmark$ & Nociones \\
& Elementales \\
de Historia, & principalmente la \\
del país & $\checkmark$ \\
$\checkmark$ & Dibujo Lineal \\
$\checkmark$ & Nociones de \\
& Partida Simple y \\
& Doble
\end{tabular} & $\begin{array}{l}\text { Primer grado: } \\
\text { Lectura, Caligrafía, Aritmética, Enseñan- } \\
\text { za Objetiva, Ejercicios militares y Canto. } \\
\text { § Si la escuela fuere de niñas tendrá } \\
\text { en vez de la de Ejercicios militares la } \\
\text { clase de Labores de mano, debiendo } \\
\text { ser obligatoria en todos los grados, y ser } \\
\text { enseñada por espacio de una hora diaria } \\
\text { por lo menos. } \\
\text { Segundo grado: } \\
\text { Lectura, Caligrafía, Aritmética, Enseñan- } \\
\text { za Objetiva, Canto, Geografía, Historia } \\
\text { Sagrada y Gimnasia ó Calistenia } \\
\text { §En las escuelas de varones es obligatoria } \\
\text { además la clase de Ejercicios militares en } \\
\text { todos los Grados. } \\
\text { Tercer grado: } \\
\text { Lectura, Caligrafía, Aritmética, Enseñan- } \\
\text { za Objetiva, Canto, Geografía, Historia } \\
\text { Sagrada, Gimnasia, Gramática Castella- } \\
\text { na, Geometría y Dibujo. } \\
\text { Cuarto grado: } \\
\text { Lectura, Caligrafía, Aritmética, Canto, } \\
\text { Geografía, Historia Sagrada, Gimnasia, } \\
\text { Gramática Castellana, Geometría, Dibu- } \\
\text { jo, Historia Patria y Elementos de Fisiolo- } \\
\text { gía y Zoología } \\
\text { § Si la escuela fuere de niñas, deberá } \\
\text { tener en este grado, además, Ia clase } \\
\text { de Economía Doméstica, para que sea } \\
\text { continuada en el quinto y sexto. } \\
\text { Quinto grado: } \\
\text { Lectura, Caligrafía, Aritmética, Canto, } \\
\text { Geografía, Historia Sagrada, Gimnasia, } \\
\text { Gramática Castellana, Geometría, Dibu- } \\
\text { jo, Historia Patria, Fisiología, Zoología, } \\
\text { Física, Cosmografía, Inglés y Educación } \\
\text { Cívica ó Cartilla del Ciudadano. } \\
\text { Gimnasia, Galigrafía, Aritmética, Canto, } \\
\text { jo, Zoología, Botánica, Faśsica, Historia } \\
\text { Patria, Cosmografía, Inglés, Francés, } \\
\text { Historia Universal y Elementos de Agri- } \\
\text { cultura. }\end{array}$ \\
\hline
\end{tabular}

Fuente: Elaboración propia a partir de los diferentes reglamentos de instrucción pública. 
Cuadro 4: Promedio de escuelas públicas para cada Inspector, 1890

\begin{tabular}{l|l|l}
\hline \multicolumn{1}{c}{ Inspector } & \multicolumn{1}{c}{ Departamentos } \\
\cline { 1 - 2 } Justiniano R. Núñez & $\begin{array}{l}\text { San Salvador } \\
\text { Cuscatlán }\end{array}$ & \\
\hline Francisco E. Boquín & $\begin{array}{l}\text { Santa Ana } \\
\text { Ahuachapán }\end{array}$ \\
\cline { 1 - 2 } Luis A. Quintero & $\begin{array}{l}\text { Sonsonate } \\
\text { La-Libertad }\end{array}$ & \\
\hline Rafael Castillo & $\begin{array}{l}\text { La-Paz } \\
\text { San Vicente }\end{array}$ & \\
\hline Felipe Solano & $\begin{array}{l}\text { Chalatenango } \\
\text { Cabañas }\end{array}$ \\
\hline Francisco Campos & $\begin{array}{l}\text { San Miguel } \\
\text { Usulután }\end{array}$ \\
\hline Francisco Cruz & $\begin{array}{l}\text { La-Unión } \\
\text { Morazán }\end{array}$ \\
\hline
\end{tabular}

Fuente: Elaboración propia a partir de: La Nueva Enseñanza, 4, Marzo de 1890, pp. 1-7. 